\title{
ECONOMIA E EMPREENDEDORISMO ÉTNICO: BALANÇO HISTÓRICO DA EXPERIÊNCIA PAULISTA
}

\section{RESUMO}

Este artigo procura comentar as principais relações entre dois temas distintos: o da atividade empresarial e o da etnicidade. Além de substantivamente diferentes, eles são ainda normalmente tratados sob disciplinas e tradições acadêmicas diferenciadas: da prática da atividade empresarial ocupam-se normalmente economistas e administradores; com o tema da etnicidade preocupam-se antropólogos, sociólogos e historiadores. Com o recente desenvolvimento de trabalhos nas áreas tanto de Cultura Organizacional como de Sociologia Econômica, aproximações entre os dois campos se estabeleceram, permitindo um tratamento menos setorial do assunto. O empreendedorismo étnico ganhou, assim, relevância entre os estudiosos da sociologia econômica e redes ao reconhecerem que os recursos e as possibilidades de emprego dos imigrantes estão em suas próprias comunidades étnicas, permeadas por redes de relacionamento e capital social. Mais do que afirmar algo de conclusivo, este trabalho procura explorar as possibilidades de estudos associadas ao tema, tomando por base referências à experiência paulista.

\section{Oswaldo Mário Serra Truzzi \\ UFSCar}

\section{Mário Sacomano Neto}

UNIMEP

\begin{abstract}
This paper relates two distinct themes: entrepreneurship and ethnicity. They are normally treated by different academic traditions: economists and businessmen deal with the first, while anthropologists, sociologists and historians usually investigate the latter. Due to the recent development of areas like Organizational Culture and Economic Sociology, approximations between these two themes have occurred, allowing a conjoint treatment of them in the field defined as ethnic entrepreneurship. Studies in this new area recognize that many resources and job possibilities for immigrants are available at their own communities, where networks of social capital pervade. More than driving definite conclusions, this work explores some insights in this area, taking São Paulo's historical socio-economic experience as reference.
\end{abstract}

PALAVRAS-CHAVE Economia étnica, empreendedorismo étnico, sociologia econômica, redes, capital social. KEYWORDS Ethnic economy, ethnic entrepreneurship, economic sociology, networks, social capital. 


\section{INTRODUÇÃO}

Tornou-se redundância afirmar o papel decisivo dos empreendedores no capitalismo. Dotados de sensibilidade em detectar tendências e nichos a serem explorados no tecido econômico, empreendedores são os agentes que, na perspectiva schumpeteriana, concebem inovações e organizam a atividade produtiva, impulsionando a economia.

Historicamente, analisando-se a experiência de conformação da indústria nacional e em especial paulista - sua base geográfica mais importante-, observa-se que a matriz do empresariado originou-se basicamente da experiência de recepção de imigrantes, inaugurada a partir do final do século passado. Por certo, a maioria deles veio a São Paulo na condição de colonos, na expectativa de, após alguns anos de trabalho na lavoura cafeeira, tornarem-se proprietários rurais. Mas também é certo que o desenvolvimento da economia e do complexo cafeeiro impulsionou as atividades industriais. Num primeiro momento, a indústria acompanhou e dependeu do desenvolvimento do café para, em seguida, afirmar-se como fonte de acumulação endógena, alimentada por si própria, independendo deste.

Que imigrantes estiveram à frente da experiência de industrialização em São Paulo? Dean (1971) mostrou que, de modo geral, dedicaram-se aos primórdios da atividade industrial aqueles que ou vieram já com algum capital, ou já detinham algum tipo de experiência comercial ou artesanal na terra de origem, ou que aqui haviam adquirido alguma experiência no comércio importador, passando mais tarde a tentar produzir o que antes era importado (Martins, 1979). Inevitável que neste ponto se toque na questão do quase monopólio do trabalho qualificado e do êxito dos imigrantes a partir do comércio miúdo e da pequena oficina. O casamento entre habilidades prévias e oportunidades que passaram a existir no país em grande parte favoreceu a inserção de parcelas de imigrantes em atividades empresariais, processo ainda mais facilitado tanto pelo pouco interesse e mesmo desprezo das elites agrárias tradicionais por atividades não relacionadas à agricultura, quanto pela pouca concorrência da mão de obra de origem escrava.

Apoiado em levantamento empírico realizado entre empresários de médio e grande porte da capital e da região do ABC em 1962, o estudo de Bresser-Pereira, um dos raros trabalhos destinados a esmiuçar a origem étnica e social de empresários, chega a conclusões que reforçam a relação empresário-etnia. O autor conclui pela origem étnica esmagadoramente estrangeira dos empresários (84,3\%), entendendo-se como incluídos nessa categoria os filhos e netos de imigrantes. Identifica ainda a extração predominantemente de classe média desse empresariado, localizando nas economias familiares a proveniência do capital inicial utilizado para a abertura das empresas. Dessa forma, embora Bresser-Pereira preste pouca atenção aos impulsos à industrialização ocorridos nas duas décadas anteriores à crise de 1929, termina por afirmar que sua pesquisa constitui uma demonstração vigorosa de que a crise de 1929 impediu a transferência direta de investimentos da agricultura cafeeira para atividades industriais. Como a agricultura cafeeira estava sob a égide dos fazendeiros, que formavam a base da oligarquia agrícola comercial dominante até 1930, conclui-se que o promotor por excelência da atividade industrial não teria sido o fazendeiro de café, mas o imigrante (Pereira, 1964).

Essa constatação foi muitas vezes corroborada por estudos de história local e regional realizados no interior de São Paulo, como o que se empreendeu, por exemplo, ao analisar São Carlos. Município desenvolvido nos marcos da economia cafeeira, fortemente tributário da imigração italiana, não se observa ali um único caso de fazendeiro que tenha investido em atividades industriais a partir dos anos 1940, quando a cidade se industrializou (Truzzi, 1986).

Se a industrialização paulista deve grande parte de seu vigor à capacidade empreendedora dos imigrantes, tomados em seu conjunto, uma análise mais cuidadosa da participação de cada etnia específica no processo de industrialização pode revelar relações difíceis de captar quando se analisa a totalidade dos estrangeiros empreendedores em São Paulo. Por esse fato, a sociologia econômica contribui de forma significativa ao estudo do empreendedorismo étnico ${ }^{1}$ ao chamar a atenção para as relações existentes entre a economia e a sociedade. As redes de relacionamentos e o capital social estabelecido entre os imigrantes fornecem subsídios para um entendimento mais cuidadoso do tema.

\section{SOCIOLOGIA ECONÔMICA}

Segundo Swedberg (1993), a sociologia econômica surgiu com Max Weber no fim do século XIX, que se preocupou profundamente com a polarização entre um braço histórico e outro analítico nas análises econômicas, levando assim à chamada "guerra dos métodos" (Methodenstreit). Outras contribuições, de Émile Durkheim, Karl Marx e Karl Polanyi, foram substancialmente importantes para se entender a estrutura social de troca nos mercados modernos. Esses autores contribuíram contrapondo-se à idéia de 
que a esfera econômica é suficientemente autônoma em relação à esfera social, como acreditavam os economistas clássicos (Granovetter, 1985).

Por definição, a sociologia econômica é entendida por meio da utilização da estrutura de referências, variáveis e formas de explanação da sociologia em atividades complexas relacionadas com a produção, distribuição, troca e consumo de recursos escassos e serviços (Smelser e Swedberg, 1994). Atualmente, a sociologia econômica contribui de maneira expressiva para a análise organizacional, no sentido de compreender o modo como os atores econômicos, apesar de seus interesses, são condicionados pela interação e pela estrutura social. Um conjunto de temas surge a partir dessa proposição, para se compreender que a arena econômica é formada por muitos mecanismos sociais, como confiança, cooperação e competição (Swedberg, 1993).

Compreender a relação entre a ação econômica e a estrutura social é o que motiva, em parte, o trabalho de Granovetter (1985), que utiliza o conceito de embeddedness (imersão) para ilustrar o modo como as relações sociais condicionam o comportamento econômico e as instituições. O autor diferencia e critica duas concepções do homem econômico, ou ator econômico, utilizando dois conceitos: o primeiro é o oversocialized, que compreende que os atores obedecem a normas e valores consensualmente desenvolvidos, por meio da socialização; o segundo é o undersocialized, que compreende que os atores não sofrem nenhum impacto da estrutura social nem das relações de produção, distribuição ou consumo. Granovetter (1985) critica ambas as concepções por considerarem o caráter atomístico dos atores. Na verdade, os atores não decidem como átomos independentes e também não aderem inteiramente a normas implícitas, desconsiderando seus interesses. Na perspectiva do embeddedness, os atores têm uma ação intencional dentro do sistema de relações sociais (Granovetter, 1985). O autor destaca ainda que a ação econômica e de resultados é afetada por pares de atores e pela estrutura geral da rede.

A partir do trabalho de Granovetter, muitos outros autores têm se debruçado sobre o conceito de embeddedness para compreender um conjunto significativo de aspectos, entre eles: Uzzi (1996, 1997), Grabher (1993), Gnaywali (2000), Rowley, Behrens e Krackhardt (2000). A perspectiva do embeddedness busca demonstrar como a estrutura de troca nos mercados está embutida em processos sociais complexos (Dacin, Ventresca e Beal, 1999). Como destacado por Zukin e Dimaggio (1990), existem quatro tipos de embeddedness: político, cognitivo, cultural e estrutural. $\mathrm{O}$ embeddedness político observa os limites institucionais do poder econômico e dos incentivos; o cognitivo observa os processos da estrutura mental na lógica econômica; o cultural considera que as crenças e os valores suportam a ação econômica (Uzzi, 1996); e, por fim, o embeddedness estrutural preocupa-se com a qualidade do material e a estrutura de conexões entre os atores.

A sociologia econômica tem um amplo conjunto de temas e questões que contribuem para o estudo da economia e do empreendedorismo étnico. A começar pela indissociação entre economia e sociedade. No caso do empreendedorismo étnico, os atores estão imersos (embedded) pela interação, pela estrutura social e pelos mecanismos sociais, principalmente a confiança e a cooperação.

\section{REDES ÉTNICAS E CAPITAL SOCIAL}

As relações densas e difusas são denominadas por Burt (1992) capital social. Segundo o autor, a arena competitiva tem uma estrutura social: atores confiando em outros atores, obrigados a suportar outros, dependentes de trocas com outros. Cada ator tem suas redes de contatos. A posição ocupada por um ator na estrutura social da arena proporciona vantagens e posições privilegiadas.

Questões empíricas dessa linha de trabalho voltamse para a magnitude de associações entre recursos de contato e o próprio recurso do ator, e para as variações nas associações por meio dos tipos de relações (Burt, 1992). Evidências empíricas estão fartamente disponíveis. As pessoas desenvolvem relações com pessoas similares ou com as quais se identificam. Existem razões óbvias para isso: as pessoas socialmente similares passam o tempo nos mesmos lugares, e as relações entre elas assim emergem. Além disso, as pessoas socialmente similares têm mais interesses em comum, e assim as relações são mantidas. A opinião e os recursos de um indivíduo estão relacionados com as opiniões e os recursos de seus contatos estreitos (Burt, 1992). Essa caracterização é de fato muito clara dentro dos empreendedores étnicos.

O primeiro tipo de capital social é denominado por Burt (1992) buraco estrutural. Esse termo foi utilizado para descrever a posição que um ator pode ocupar entre contatos não redundantes. Os buracos estruturais proporcionam benefícios aos atores que ocupam essa posição na rede. Esses atores intermediários também são conhecidos como brokers. Então, para os setores dinâmicos, onde as inovações tecnológicas são rápidas, são necessárias informações não redundantes, promovidas normalmente por redes difusas. 
A outra forma de capital social das redes são as relações cooperativas, também entendidas como strong ties, particularmente relevantes para o estudo das redes étnicas. Diferentemente dos buracos estruturais, as relações cooperativas encerram informações redundantes, normas de confiança, previsibilidade das relações e contratos de longo prazo. Maior coesão e densidade permitem a troca de informações refinadas, reciprocidade, normas cooperativas, etc. Essas relações fortes e duradouras podem, entretanto, dificultar o acesso dos atores às novas informações que circulam fora daquele ambiente restrito.

As redes e a economia étnica encerram, por natureza, relações coesas entre os participantes da comunidade. Diversos autores têm sugerido que um dos recursos mais importantes que as comunidades possuem é o capital social que está diretamente associado a taxas mais elevadas de sucesso nos negócios (Martes e Rodrigues, 2004). Comunidades com alto capital social proporcionam aos atores acesso a informações privilegiadas, recursos e, ainda. um esforço cooperativo para o desenvolvimento dos negócios. Esse fato influencia de forma significativa o desenvolvimento e a formatação da estrutura social e econômica de determinadas regiões.

\section{CULTURA EM ORGANIZAÇס̃ES ÉTNICAS}

A partir dos anos 1980, o tema da cultura organizacional se popularizou nos compêndios de Administração. Até então, mesmo de um ponto de vista sociológico, as organizações tradicionalmente eram encaradas como estruturas sociais pouco afetadas por determinantes culturais. A maior parte das organizações era vista como submetida a uma regra geral de eficiência de aplicação universal e não a condicionantes culturais específicos. Nesse sentido, as empresas sempre tenderam a ser apreendidas como o domínio do não-simbólico, no sentido de que estão mais inclinadas a refletir leis econômicas universais do que hábitos sociais locais. A fórmula se coaduna melhor com os praticantes de uma ciência administrativa ávidos por receitas de aplicação universal, mesmo que tais receitas, ao cabo de alguns anos, sejam suplantadas por outras, gerando o fenômeno da sucessão de modismos na administração.

Existirão pressupostos transcendentais de racionalidade que determinam as características centrais das organizações ou será a racionalidade no interior das organizações um subproduto cultural sujeito a idiossincrasias? (Dobbin, 1994). Essa dicotomia interpretativa entre uma corrente de pensamento que toma a racionalidade das organizações como fenômeno "acultural" e outra que a percebe como conjunto de práticas e comportamentos inclusive os da empresa moderna - que são artefatos culturais pode ser vista como resultante da influência do pensamento de Max Weber. Ao discorrer a respeito da crescente importância das burocracias racionalizadas no mundo ocidental, Weber as descreve em termos de um tipo ideal poderoso, cuja lógica e modus operandi implacáveis de certo modo refletem um desenvolvimento superior em termos de formas organizacionais. Ao fixar que as burocracias racionais-legais obedecem a regulamentos e regras, definidas segundo esferas de competência, hierarquizadas e especializadas em carreiras, Weber incentiva leituras dispostas a sugerir e a enfatizar a aplicação de princípios de validade universal para a empresa moderna. Por outro lado, e em contraste com a perspectiva anterior, Weber, em seus trabalhos sobre religião, associa as origens da conduta racional acumulativa em que se baseia a empresa moderna não a um conjunto de leis econômicas universais capazes de ditar parâmetros de eficiência, mas a circunstâncias relacionadas à evolução do protestantismo no Ocidente. Mais ainda. Em seus escritos metodológicos, Weber insiste em que todo comportamento social é indeterminado e que todas as práticas sociais apenas podem ser compreendidas por meio de interpretações, ou seja, nunca o significado pode se referir a algo objetivamente "correto" ou "verdadeiro" em algum sentido metafísico. Nos últimos anos, a emergência de um vasto corpo de literatura empenhado em relativizar pressupostos de racionalidade tomados como universais, e em desenvolver o tema das culturas organizacionais na empresa moderna, sugere que a resposta à pergunta formulada no início do parágrafo inclina-se para a segunda alternativa.

De um ponto de vista mais instrumental, a administração moderna passou a se interessar pelo tema de culturas organizacionais à medida que este fornecia um enfoque inovador para o problema da doutrinação e do envolvimento de todos os escalões da empresa com os objetivos gerais definidos pela cúpula. O que está em jogo é a difusão não espontânea de valores, atitudes e práticas administrativas valorizadas pelas empresas. Numa perspectiva mais interessante, Etzioni (1974), ao tratar da questão dos tipos de poder utilizados para garantir o envolvimento do indivíduo nas organizações, referia-se a três possibilidades: coercitivo, remunerativo e normativo. A temática hoje referida como cultura organizacional vincula-se claramente a este último tipo.

O problema da formação e da difusão de culturas em organizações pode ser apreendido a partir dos níveis in- 
terno e externo, isto é, a questão pode ser enfocada nos contextos intra-organizacional e interorganizacional. De um ponto de vista do interior da empresa, a formação da cultura organizacional parece resultar de uma bem-sucedida percepção compartilhada ${ }^{2}$ de enfrentamento de determinada situação. Essa é pelo menos a posição dos autores que optam por utilizar uma abordagem do tema cuja ênfase recai sobre mecanismos de integração, em contraposição a outros que preferem privilegiar a dinâmica do poder disputado por diferentes subculturas (diferenciação), ou ainda a alguns que acentuam a complexidade e multiplicidade de pontos de vista não compartilhados (fragmentação) (Martin, 1992). Embora simplificadora, a visão integradora é mais operacional para nossos fins. Schein, por exemplo, define cultura organizacional como o conjunto de

[...] pressupostos básicos - inventados, descobertos ou desenvolvidos por um determinado grupo quando este aprende a lidar com seus problemas de adaptação externa e integração interna - que funcionaram suficientemente bem para ser considerados válidos e, portanto, para serem ensinados aos novos membros como o modo correto de perceber, pensar e sentir em relação a esses problemas. (SCHEIN, 1985, p. xx).

Por isso, duas considerações influenciam de modo decisivo a formação da cultura em uma empresa. Uma diz respeito ao papel do líder ou fundador, porque em grande medida ele é o responsável pelo modo como a situação é apreendida e enfrentada, além de deter a iniciativa para mobilizar recursos e pessoas. A outra consideração envolve o ambiente maior no qual a empresa está inserida, sobretudo no que se refere aos condicionantes tecnológicos e de mercado, responsável por lançar desafios e parametrizar condicionantes sob os quais a empresa opera (Ferro, 1991; Fischer, 1989).

De um ponto de vista interorganizacional, a difusão de uma cultura comum entre empresas se associa menos às vicissitudes do fundador ou líder de cada uma delas e mais a uma experiência comum de enfrentamento de condições lançadas pelo ambiente. Além disso, à medida que outras práticas empresariais são adotadas e difundidas, o campo torna-se mais homogêneo, não porque as práticas empresariais tendam a convergir para um modelo racional mais perfeito, mas porque as escolas, a mídia, as associações e outras instituições de influência no mundo empresarial difundem isomorfismos que acabam sendo adotados por conjuntos de empresas (DiMaggio e Powell, 1991).

\section{UMA ECONOMIA ÉTNICA}

No plano do desenvolvimento recente da assim chamada economia étnica, dentro da sociologia econômica, que novos insights pode nos trazer essa abordagem para a relação entre empresários e etnicidade? Algumas das características de uma economia étnica apontadas pela literatura incluem integração e cooperação étnica, fontes étnicas de capital, trabalho e informação, restrições a competição intragrupo, especialização ocupacional, concentração geográfica, solidariedade étnica e confiança em redes internacionais de base étnica (Gold, 1989).

Curiosamente, a exemplo do debate relativo à cultura organizacional, o conceito de economia étnica também guarda distâncias em relação à racionalidade puramente capitalista, moderna e impessoal, ainda que seja incapaz de transcendê-la, operando claramente dentro de seus marcos. Esta se caracterizaria por evitar relações pessoais privilegiadas, inclusive as que se baseiam em vínculos étnicos. Num outro pólo, a noção de economia étnica também recebe influência do conceito bastante utilizado na literatura americana de middleman minorities, traduzido aqui livremente por minorias mercantis. ${ }^{3} \mathrm{O}$ termo se refere a determinados grupos étnicos que historicamente se especializaram no comércio e na intermediação em sociedades pré-capitalistas, e cuja vocação é mantida até hoje. Judeus e armênios representariam os exemplos clássicos.

Uma definição mais operacional do conceito de economia étnica requer defini-la como qualquer conjunto de empregadores, auto-empregados ou simplesmente empregados pertencentes a um mesmo grupo étnico ou de imigrantes (Bonacich e Modell, 1980). Dessa forma, toda minoria mercantil tem uma economia étnica, mas não vice-versa. Este último conceito torna-se mais operacional porque é mais abrangente, no sentido de dar conta de outros grupos não historicamente identificados como minorias mercantis e de sua utilização poder se aplicar também a sociedades capitalistas avançadas.

A análise de uma economia étnica, isto é, de um ramo de negócios que opera segundo os critérios e características acima apontados, nos instrumenta a distinguir se um grupo, ao se hospedar em determinada economia, o fez majoritariamente capturando empregos já disponíveis ou criando e enxertando novas firmas e empregos na economia hospedeira. Uma série de estudos mostra que, para um determinado grupo, o equilíbrio entre essas duas estratégias - aproveitar oportunidades já oferecidas pelo mercado de trabalho ou criar oportunidades de auto-emprego - resulta em diferenças essenciais do ponto de vista 
da mobilidade econômica. Não há uma regra universal, e tudo depende da comparação entre níveis de remuneração dentro e fora do setor definido como operando nos termos de uma economia étnica. Há casos em que todos ganham ao se manterem fora do mercado de trabalho mais geral e no interior da economia étnica. Mas há outros em que os beneficiados são apenas os empregadores, enquanto seus empregados conterrâneos são explorados. Outro caso comum é quando todos - empregadores, auto-empregados e empregados - são mais mal remunerados no interior da economia étnica do que os conterrâneos inseridos fora dela. Entretanto, como o mercado de trabalho em geral não abriga a todos, a inserção na economia étnica livraos do desemprego. Nesse caso, numa situação de pleno emprego, a economia étnica não se sustentaria (Light, 1994). Uma interessante decorrência disso é que, ao contrário da noção mais comum proclamada pela teoria da assimilação, esta nem sempre incrementa a mobilidade. Muitas vezes, o auto-emprego étnico torna mais rentável à não assimilação do que à assimilação.

De qualquer forma, economias étnicas grandes e lucrativas exigem forte capacidade empresarial, ou seja, dependem da habilidade do grupo em explorar condições de demanda favoráveis. Os sociólogos em geral tenderam a explorar o lado da oferta, isto é, o modo como tais habilidades, transformadas em capacidades empresariais, foram formadas e se disponibilizaram. Numa outra perspectiva, os economistas investiram mais em explicar o mesmo fenômeno pelo lado da demanda: uma economia étnica emerge quando as atividades empresariais étnicas são valorizadas pelo mercado. Isso pode ocorrer nos casos em que o mercado incentiva as ofertas de serviços de consumo especiais para conterrâneos, o aparecimento de pequenos e médios negócios em meio ao tecido empresarial, a substituição de grupos étnicos estabelecidos anteriormente; ou, ainda, quando existem políticas governamentais etnicamente orientadas que incentivam a abertura de firmas.

Ainda que interessantes, as explicações pelo lado da demanda são insuficientes para explicar por que, de modo geral, os grupos étnicos exibem taxas mais altas de auto-emprego do que os nativos, e também por que certos grupos étnicos apresentam desempenho melhor que outros. Sempre é bom lembrar que as demandas devem ser percebidas, reconhecidas ou descobertas pelos empreendedores, o que nos remete imediatamente à discussão de um equipamento cognitivo adequado e dos recursos disponíveis para o aproveitamento das oportunidades. Alguns autores recomendam então um enfoque interativo capaz de explorar as congruências entre demandas do ambiente econômico e recursos informais da população étnica (Waldinger, 1985).

Do lado dos recursos, boa parte deles diz respeito ao acesso a capital financeiro e humano. Desse ponto de vista, as desigualdades no aproveitamento de oportunidades entre grupos étnicos distintos refletiriam a circunstância de que alguns grupos são mais pobres, discriminados ou vitimados do que outros, impedindo-os de emprestar ou economizar recursos financeiros necessários às atividades empresariais. O problema desse argumento é que a maior parte dos recursos financeiros empregados na abertura de firmas entre grupos étnicos não resulta de empréstimos de fora, mas de economias mobilizadas pelo próprio dono, sua família, amigos e conterrâneos. Por sua vez, como tanto a capacidade de poupar como a de mobilizar redes são variáveis em última análise culturalmente determinadas entre diferentes grupos, alguns fornecem empresários com maior abundância que outros. De modo semelhante, é possível se perseguir o mesmo tipo de determinante, de fundo cultural, nas explicações que privilegiam desigualdades na disponibilidade não de capitais financeiros, mas de capital humano entre grupos.

Para explicar capacidades empresariais distintas, vários pesquisadores recorrem a explicações que enfatizam os recursos de classe e os recursos étnicos. Os recursos de classe dizem respeito a atributos materiais e culturais inerentes à burguesia de um grupo que a impulsionam para exercer atividades empresariais. A pertinência à classe burguesa já no país de origem se reproduziu no país de destino.

Já os recursos étnicos dizem respeito a aspectos socioculturais e demográficos de todo o grupo, e não apenas de sua fração burguesa, que incentivam atividades empresariais. Existem etnias que evitam o trabalho assalariado, a não ser de forma temporária e como perspectiva para o estabelecimento do negócio próprio. No caso dos imigrantes judeus, por exemplo, em quase todo o mundo, praticamente toda a comunidade aspirava numa determinada época ao auto-emprego, e não apenas uma fração burguesa do grupo étnico. Neste caso, a aspiração para tornar-se empresário constituiu um recurso étnico, e não apenas de uma classe.

Os recursos étnicos podem ser mais bem explorados quando integrados por uma rede. As redes de imigração podem ser caracterizadas como conjuntos de laços interpessoais que ligam migrantes, pioneiros migrantes e não migrantes, em áreas de origem e destino, por meio de vínculos de parentesco, amizade e conterraneidade. $\mathrm{O}$ estudo das redes étnicas constitui um tópico de particular interesse porque possibilita conectar os determinantes da imigração aos níveis micro e macro. 


\section{ECONOMIA ÉTNICA NO ESTADO DE SÃO PAULO}

A imigração de origem italiana, por ser a mais numerosa, foi responsável por parcela muito significativa das empresas fundadas por imigrantes em todo o estado. Como os italianos inauguraram a imigração em massa a São Paulo e se disseminaram por toda a parte, é natural que, com seu pioneirismo, tenham ocupado um espaço privilegiado em segmentos muito diversos do tecido industrial em formação. Mesmo que a colônia tenha nas figuras de Matarazzo, Crespi, Pinotti Gamba e outros a identificação mais popular do binômio italianità-indústria, a influência dos italianos na formação do parque empresarial paulista se estendeu muito além de seus grupos econômicos historicamente mais famosos.

Um pouco diverso é o caso dos empresários de origem portuguesa, em função de que o fluxo migratório se compôs de dois contingentes nitidamente distintos, um rural e outro urbano. No meio rural, não se pode dizer que a presença de portugueses tenha sido importante. Porém, no ambiente urbano os portugueses deixaram uma marca indelével em várias regiões do Brasil, sobretudo à frente de atividades comerciais. Em termos regionais, a presença de empresários portugueses ocorreu de forma muito marcante no Rio de Janeiro. Porém, mesmo em São Paulo, o comércio atacadista de tecidos, estabelecido no início do século à Rua Florêncio de Abreu, foi implantado por firmas portuguesas, muitas abastecidas por firmas de conterrâneos instaladas na então capital federal.

Além do setor têxtil, negócios de portugueses proliferaram no comércio atacadista e varejista, por vezes importador e exportador, de gêneros alimentícios e matérias-primas nacionais. De fato, o comércio constituiu a esfera por excelência dos negócios de portugueses no Brasil, provavelmente porque a maior parte não dispunha de recursos suficientes, conexões ou tecnologia para se aventurar com maior profundidade em atividades industriais. ${ }^{4}$ De um ponto de vista cultural, Pescatello sugeriu ainda que os portugueses preferiram o comércio por este ser uma empresa muito mais sujeita a contatos pessoais, mais condizentes com a índole deste imigrante, do que a indústria (Pescatello, 1970).

Isso se reflete até os dias de hoje na ocorrência de grupos econômicos capitaneados por empresários de origem portuguesa dominando grandes redes de distribuição e de supermercados, a exemplo de Martins (Armazéns Martins), Diniz (Grupo Pão de Açúcar), Veríssimo (Grupo Eldorado), Artur Sendas (Grupo Sendas). Graças a essa presença significativa no meio citadino, autores como
Klein (1991) puderam observar que a imigração portuguesa no Brasil acabou resultando, comparativamente a outros grupos étnicos, em uma estrutura ocupacional mais complexa, e em um padrão de mobilidade menos determinado unicamente pelo acesso à propriedade no meio rural.

Atrás de italianos e portugueses, o terceiro grande contingente de imigrantes chegados a São Paulo pouco se notabilizou por suas capacidades empreendedoras. Os espanhóis, embora tenham assumido um papel de muita relevância entre as lideranças do movimento operário no início do século passado, raramente ousaram realizar incursões mais conseqüentes na propriedade de firmas comerciais e industriais paulistas. A maior parte de suas firmas eram pequenas e pouco capitalizadas, e se tivéssemos que apontar um nicho de mercado dominado pela etnia haveria alguma dificuldade. Não por acaso, a única referência disponível de um ramo econômico no qual os espanhóis tenham se concentrado em São Paulo é o de firmas especializadas em trabalhos de demolição, acompanhadas da comercialização de ferro-velho. Após sugerir que a fraca destinação urbana e os altos índices de analfabetismo associados ao grupo podem ter debilitado sua capacidade empresarial, Klein (1994) conclui que é evidente que os espanhóis foram lentos em se tornar empresários, apesar de sua importância numérica na população imigrante.

À parte as três etnias majoritárias, responsáveis pelo fluxo principal de imigrantes chegados a São Paulo, chamam a atenção as assim chamadas etnias comerciais, compostas predominantemente por libaneses, sírios e judeus. São grupos marcados por uma acentuada destinação urbana, que experimentaram uma trajetória de mobilidade socioeconômica muito forte, em geral iniciada pela mascateação, e que, desenvolvida do pequeno ao grande comércio varejista e atacadista, floresceu em alguns setores industriais. No comércio, dedicaram-se em profusão aos armarinhos, roupas prontas e artigos têxteis de modo geral. $\mathrm{Na}$ indústria, prosseguiram em setores afins, como o de confecção e o têxtil. O que distingue tais grupos frente à experiência das etnias majoritárias é a forte articulação interna das colônias, alimentada por um sentido de identidade religiosa, familiar ou de conterraneidade capaz de prover uma estrutura de recepção e acolhimento ao imigrante muito operativa. Ambas as colônias operaram com nichos econômicos verticalmente integrados, embora entre sírio-libaneses e judeus despontem algumas diferenças dignas de nota: enquanto os primeiros vieram a partir dos últimos anos do século XIX e se espalharam por todo o território nacional, os judeus chegaram principalmente a 
partir dos anos 1920 e tenderam a se concentrar na capital paulista (Truzzi, 1996).

A Tabela 1 atesta o volume e distribuição no estado, por nacionalidade, das empresas cujos proprietários eram estrangeiros, em 1934. Embora imprecisa porque abrigue sob a alínea brasileira grande número de empresas lideradas por filhos de estrangeiros nascidos no Brasil, ela nos fornece algumas indicações sobre a relação empresário-etnia naquela época.

Em primeiro lugar, apesar da distorção mencionada, é interessante notar que, mesmo assim, quase metade (44\%) das empresas pertencia a estrangeiros. Dessas, $58 \%$ pertenciam a italianos e $12 \%$ a portugueses, perfazendo um subtotal de $70 \%$. Os espanhóis confirmam seu reduzido desempenho por estarem à frente de empresas de pequeno porte e pouco capitalizadas. Para uma avaliação dos japoneses, chegados tardiamente, em 1934, ainda é muito cedo. Em seguida, desconsideradas as empresas canadenses, inglesas e americanas, cujos porte é elevado devido ao fato de operarem basicamente nos setores de fornecimento de energia, ferrovia e telefonia, muitas vezes em regime de monopólio, salta aos olhos o tamanho médio das empresas pertencentes a sírios e libaneses. O tamanho pode ser aferido em função do capital médio investido por empresa, do número médio de operários, da capacidade energética instalada ou do valor médio da produção. Infelizmente, poloneses e russos, as nacionalidades que supostamente mais abrigariam judeus, encontram-se incluídos na categoria outras.

Frente a esse quadro de significativa importância do estrangeiro na composição do empresariado paulista, acreditamos que o tema mereça ser mais detidamente investigado, à luz dos desenvolvimentos recentes nas áreas de sociologia econômica e cultura organizacional, e para tanto passamos a estabelecer alguns nexos e considerações.

\section{CONSIDERAÇÕES SOBRE O CASO PAULISTA}

À luz desses desenvolvimentos recentes, como situar a relação empresários-etnicidade na experiência paulista? O que há de novo nas considerações teóricas acima mencionadas? O restante deste artigo se orienta por essas indagações.

Nas experiências paulista, brasileira e mundial, pequenos negócios parecem constituir parte importante do

Figura 1 - Tamanho médio das empresas em São Paulo segundo a nacionalidade dos proprietários (1934).

\begin{tabular}{|c|c|c|c|c|c|}
\hline $\begin{array}{l}\text { NACIONALIDADE } \\
\text { DO EMPRESÁRIO }\end{array}$ & $\begin{array}{l}\text { NÚMERO DE } \\
\text { EMPRESAS }\end{array}$ & $\begin{array}{l}\text { CAPITAL MÉDIO } \\
\text { INVESTIDO POR } \\
\text { EMPRESA }\end{array}$ & $\begin{array}{l}\text { NÚMERO MÉDIO DE } \\
\text { OPERÁRIOS POR } \\
\text { EMPRESA }\end{array}$ & $\begin{array}{l}\text { FORÇA MOTRIZ } \\
\text { MÉDIA POR } \\
\text { EMPRESA(CV) }\end{array}$ & $\begin{array}{l}\text { VALOR MÉDIO DA } \\
\text { PRODUÇÃO POR } \\
\text { EMPRESA }\end{array}$ \\
\hline brasileira & 4.837 & .413 & 31 & 39 & .350 \\
\hline italiana & 2.181 & .58 & 9 & 8 & .99 \\
\hline portuguesa & .460 & .83 & 11 & 12 & .134 \\
\hline espanhola & .275 & .37 & 7 & 4 & .86 \\
\hline sírio-libanesa & .225 & .223 & 26 & 26 & .434 \\
\hline alemã & .122 & .52 & 12 & 8 & .134 \\
\hline japonesa & 62 & 23 & 7 & 3 & .47 \\
\hline austríaca & 44 & .75 & 13 & 13 & .108 \\
\hline inglesa* & 27 & 2.522 & 69 & 145 & 1.142 \\
\hline americana* & 18 & 1.034 & 38 & 86 & 1.230 \\
\hline francesa & 13 & .72 & 17 & 13 & .200 \\
\hline canadense* & 4 & 133.028 & 2.058 & 730 & 25.363 \\
\hline outras & 307 & .187 & 19 & 12 & .244 \\
\hline Total & 8.575 & .340 & 24 & 27 & .274 \\
\hline
\end{tabular}

Obs.: Valores em contos de réis.

Fonte: Estatística Industrial do Estado de São Paulo, 1934; p. 28. 
processo de instalação num novo país. Entre imigrantes, o nível geralmente alto de auto-emprego mascara grandes variações entre grupos étnicos. $\mathrm{Na}$ primeira metade do século passado, por exemplo, observamos altos índices de auto-emprego em etnias historicamente comerciais, como sírios e libaneses, judeus e armênios. No meio termo localizam-se os portugueses e em seguida, italianos e espanhóis. Como tratar tais diferenças?

As observações de campo sugerem que, para o primeiro grupo de etnias, as assim chamadas comerciais, a capacidade empresarial está associada a um recurso étnico relacionado a cada etnia como um todo, prevalecente entre todos os seus estratos. Durante décadas, independentemente do pioneirismo ou da chegada mais tardia ao país, a esmagadora maioria dos imigrantes desses grupos visava o estabelecimento de um negócio próprio da família. É claro que houve assalariamento, mas sempre de caráter temporário, subordinado a uma estratégia de formação do primeiro pecúlio que possibilitasse a abertura do negócio próprio. Pouco importava também o porte inicial dessa firma: média, pequena, minúscula, ou ainda não estabelecida fisicamente, como no caso dos mascates, em que a firma é um baú de mercadorias. O essencial era granjear independência de ação e não condicionar o retorno da operação a um limite preestabelecido, como na relação assalariada. No dizer de um entrevistado, "todos buscávamos cuidar do nosso próprio nariz".

Parece que o mesmo não se passou entre as etnias majoritárias. Aí a aspiração de estabelecer um negócio próprio esteve muitas vezes associada não a um recurso étnico, mas a um recurso de classe. Determinados estratos com experiência comercial ou urbana anterior predispunham-se com maior facilidade a abrir suas firmas. Os casos dos industriais italianos são típicos: a começar do próprio Matarazzo, a maior parte deles detinha alguma extração social privilegiada em relação à massa de seus conterrâneos.

Que relação podemos estabelecer entre as redes de imigrantes e a instalação de uma economia étnica? As redes de imigrantes que alimentam empreendedores étnicos geram modificações na economia existente na localidade de destino. Tais modificações permitem aumentar a capacidade de absorção de novos imigrantes da mesma origem. Há pelo menos três modos distintos pelos quais as redes de migrantes incentivam uma economia étnica: (1) quando a rede se abastece com mão-de-obra co-étnica de baixo custo e estabelecem-se relações preferenciais entre firmas fornecedoras e firmas clientes; (2) quando as redes provêem informação econômica tanto para empreendedores imigrantes quanto para aspirantes; (3) quando as redes provêem acesso a vários tipos de ajuda mútua e assistência, como, por exemplo, acesso ao crédito (Light e Bhachu, 1993).

Mais uma vez, os dados disponíveis sugerem que a densidade e a eficácia das redes étnicas na defesa de um nicho econômico particular foram maiores entre etnias comerciais. Não que não houvesse redes estabelecidas no interior das outras etnias. Sabemos, por exemplo, do vigor com que proliferou o mutualismo entre italianos, portugueses e espanhóis, e que Matarazzo, por exemplo, recrutava grande parcela de seus operários junto à colônia italiana, preferindo inclusive importar conterrâneos para desempenhar funções de sua confiança. Há indícios de que os empresários portugueses e espanhóis bem-sucedidos faziam o mesmo, utilizando-se fartamente do trabalho de co-nacionais e sendo inclusive legitimados no interior de suas respectivas colônias por serem capazes de demonstrar o valor da raça frente às elites nativas.

Entretanto, do ponto de vista de formação de um nicho econômico, algumas redes se mostraram mais produtivas que outras. É verdade que, no caso de italianos, como estes estavam dispersos em quase todos os ramos econômicos, fica mais difícil vislumbrar um nicho particular a ser defendido. Mas com certeza, aí influíram principalmente componentes culturais, em alguns casos as relações de solidariedade e entreajuda vigentes no interior das colônias, o grau em que tais relações se institucionalizaram, e a capacidade dos grandes empresários em abrir espaço para uma cadeia de empresários médios e pequenos conacionais. Neste último caso, o exemplo de Jafet entre os libaneses é típico. Por outro lado, os judeus representam o caso extremo de uma colônia altamente integrada, com instituições de auxílio mútuo construídas, inclusive, com apoio razoável de organizações internacionais da própria etnia (Truzzi, 2001).

De qualquer forma, as características mais importantes dos imigrantes para se estabelecerem com seus próprios negócios parecem ter sido as habilidades trazidas, o caráter permanente, em contraposição ao temporário, da imigração e, sobretudo, a capacidade de mobilizar redes e recursos étnicos. De comum, havia o obstáculo em penetrar em setores econômicos já explorados, restrição que, no caso paulista em particular e nacional de modo geral, pouco se aplicou, dado o raro interesse das oligarquias locais por atividades não relacionadas à produção de café ou de produtos agrícolas regionalmente significativos.

Assim é que os imigrantes tenderam inicialmente a se instalar em setores com poucas barreiras à entrada, como é o caso do comércio, para, aos poucos, alguns dentre os mais bem-sucedidos tornarem-se industriais. 
Teoricamente, poderíamos esperar maior dificuldade de inserção de imigrantes em ramos mais duros, com maiores exigências tecnológicas e de capital. Ainda assim, provavelmente em função do exposto anteriormente, mesmo um setor de alta composição orgânica de capital, como o da produção de papel e celulose, foi até há pouco amplamente dominado por judeus e sírio-libaneses. Isso ocorreu apesar de o setor depender decisivamente do financiamento estatal, em princípio menos ao alcance de grupos étnicos (Grun, 1994).

Outra possibilidade ilustra com particular relevância o caso mais recente de implantação de uma colônia coreana no bairro do Bom Retiro, em São Paulo. Trata-se de um caso clássico de sucessão étnica. Como sabemos, embora aberto com a finalidade de abrigar principalmente imigrantes italianos ao final do século, o bairro - ao menos em sua porção mais alta, próxima à estação ferroviária - constituiu um encrave de judeus provenientes do Leste Europeu a partir de meados dos anos 1920, boa parte deles ocupados com a comercialização e fabricação de artigos de vestuário. Com o passar dos anos, a colônia experimentou uma mobilidade econômica notável. Boa parte dos judeus deslocou suas moradias para outros bairros, como Higienópolis, chamado na colônia de Melhor Retiro. E os filhos, formados no ensino superior, adentraram em massa no mercado de profissões liberais. Sem perspectivas de sucessão, desejando melhor sorte para seus filhos, uma grande quantidade de comerciantes, alguns com 30 ou 40 anos de balcão, pouco futuro vislumbravam para a continuidade de seus negócios. Surgem então os coreanos, um grupo de imigração mais recente, razoavelmente capitalizados - inclusive com incentivos do governo coreano - e ávidos por se implantarem como pequenos empresários no tecido econômico paulistano. O resultado é uma maciça transferência de firmas dos judeus para os coreanos, nos moldes de um interessante caso de complementaridade étnica. O abandono de empreendedores prévios criou assim um espaço, no mesmo ramo, a ser preenchido (Truzzi, 2001).

Nesse caso, é claro que os judeus remanescentes se queixam dos recém-instalados coreanos. Que reclamações são freqüentes? Os judeus queixam-se basicamente da impossibilidade de competir com os coreanos no tocante ao baixo custo de sua mão de obra. Enquanto os judeus mantêm funcionários registrados, de custo mais elevado, os coreanos empregam maciçamente mão de obra familiar ou exploram conterrâneos recém-chegados, que mal se comunicam no novo país. É interessante notar que as duas práticas foram largamente exercidas pelos judeus em épocas anteriores, mas hoje não se encontram mais disponíveis para essa etnia, seja porque os familiares ganharam outro prestígio na sociedade, seja porque o fluxo migratório e por conseqüência a entrada de conterrâneos cessou. Além disso, hoje os coreanos ainda contam com a possibilidade de empregar imigrantes ilegais vindos de países vizinhos da América Latina, como paraguaios e bolivianos, os assim chamados "brasiguaios", em regime de clara exploração.

Estes, por sua vez, à medida que alguns conseguem se tornar empresários, vão formando sua própria rede de recrutamento de mão-de-obra entre imigrantes conterrâneos recém-chegados. Infelizmente até agora muito pouco pesquisadas, seria de particular interesse investigar a relação entre as estruturas formal e informal, incorporadoras de trabalho ilegal entre imigrantes. Os poucos estudos disponíveis mostram que os imigrantes ilegais tendem a ser empregados por conterrâneos, e que essa experiência prévia com emprego assalariado em firmas de co-étnicos aumenta a probabilidade de auto-emprego no mesmo setor. Dessa forma, a assim denominada empresa étnica, embora explore seus funcionários, a médio prazo parece responder pelo grande potencial de recepção, acolhimento e integração de imigrantes.

Por outro lado, a circunstância de hoje se registrar um dramático aumento de pequenas firmas subcontratadas que facilitaram a entrada de imigrantes coreanos na indústria de confecções, seja em São Paulo, Los Angeles, Berlim ou Paris, sugere uma estratégia étnica comum a ser empregada independentemente do país de destino. $\mathrm{Na}$ ausência de estudos comparativos mais cuidadosos, há indicações de que são firmas que operam segundo um mesmo padrão, tirando basicamente proveito da agilidade de responder rapidamente a demandas de produção flexível segundo flutuações da moda (Light, 1993).

Essa série de questões suscitadas pela assim chamada economia étnica sugere que investimentos interessantes de pesquisa seriam também muito bem-vindos no campo das culturas organizacionais desenvolvidas no interior de tais empresas étnicas, conforme exploramos anteriormente. A questão poderia ser colocada nos seguintes termos: trouxe a experiência empresarial imigrante alguma marca cultural para o interior das empresas cujo reflexo esclareça a seleção e a adoção de atitudes e práticas administrativas usualmente empregadas?

Os condicionantes da acumulação inicial, o emprego familiar, a experiência sucessória, as trajetórias de mobilidade entre gerações, a eficácia das redes étnicas sugerem o estabelecimento de padrões que em princípio ajudaram a delinear uma cultura empresarial brasileira, por vezes mesmo em oposição ao propalado nos livros de teoria ad- 
ministrativa. Há todo um campo a ser explorado, interno à história das empresas, carente de esforços que reúnam e dêem coerência a informações sobre os códigos próprios de socialização, modus operandi, histórias, mitos e ritos associados à marca do fundador imigrante. Num mundo crescentemente globalizado, talvez ainda fosse possível resgatar identidades e retraçar a formação de uma parcela do empresariado nacional a partir tanto da cultura quanto da qualidade das redes étnicas montadas.

Num plano mais contemporâneo, pode-se perguntar sobre a oportunidade de atualizar tais experiências. Sabemos que, sobretudo em tempos recessivos, ou de crescimento econômico modesto e com reduzida oferta de empregos formais, o mercado tende a estimular autoempreendimentos. Basta que se observe a proliferação de camelôs de origem nordestina em São Paulo. Como migrantes nacionais, eles operariam como seus antecessores estrangeiros? Com certeza, importam também parentes e conterrâneos, montam teias de informação, auto-ajuda, subemprego, etc. Existirá um aprendizado de como operar em rede que se difunde?

\section{NOTAS}

1 Não se vislumbra aqui o empreendedorismo (étnico ou de outro tipo), por mais vigoroso que seja, como algo capaz de desfazer ou solucionar as contradições entre capital e trabalho.

2 Uma das definições influentes de cultura enfatiza precisamente este aspecto: conjunto de significados compartilhados.

3 A tradução literal para o português do vocábulo "middleman" é "intermediário", "revendedor".

4 A exceção em São Paulo fica por conta do comendador Pereira Inácio, fundador do Grupo Votorantim.

\section{REFERÊNCIAS}

BONACICH, E.; MODELL, J. The Economic Basis of Ethnic Solidarity. Berkeley: University of California Press, 1980.

BURT, R. S. Structural Holes: The Social Structures of Competition. Cambridge: Harvard University Press, 1992.

DACIN, M. T.; VENTRESCA, M. J.; BEAL, B. D. The embeddedness of organizations: dialogue and directions. Journal of Management, v. 25, n. 3, p. 317-356, 1999
DI MAGGIO, P.; POWELL, W. (Eds.). The New Institutionalism in Organizational Analysis. Chicago: University of Chicago Press, 1991.

DOBBIN, F. R. Cultural models of organization: the social construction of rational organizing principles. In: CRANE, D. (Ed.). The Sociology of Culture. Oxford, UK: Blackwell, 1994.

ETZIONI, A. Análise comparativa de organizações complexas. Rio de Janeiro: Zahar, 1974

FERRO, J. R. Decifrando culturas organizacionais. Tese (Doutorado em Administração de Empresas). EAESP-FGV, São Paulo, 1991.

FLEURY, M. T. L.; FISCHER, R. M. Cultura e poder nas organizações. São Paulo: Atlas, 1989.

GNYAWALI, D.; MADHAVAN, R. Cooperative networks and competitive dynamics: a structural embeddedness perspective. Academy of Management Review, v. 26, n. 3, p. 431-445, 2001.

GOLD, S. J. Chinese-Vietnamese entrepreneurs in Southern California: an enclave with co-ethnic customers? In: PROCEEDINGS OF THE AMERICAN SOCIOLOGICAL ASSOCIATION, Anais. San Francisco, 1989.

GRABHER, G. The Embedded Firm: On the Socioeconomics of Industrial Networks. London: Routledge, 1993.

GRANOVETTER, M. S. Economic action and social structure: the problem of embeddedness. American Journal of Sociology, v. 91, n. 4, p. 491$501,1985$.

GRUN, R. Origens étnicas do empresariado e cultura organizacional brasileira. Relatório Fapesp, São Paulo, 1994. Mimeo.

KLEIN, H. The social and economic integration of Portuguese immigrants in Brazil in the late nineteenth and twentieth centuries. Journal of Latin American Studies, v. 23, n. 2, p.321, mai. 1991.

KLEIN, H. A imigração espanhola no Brasil. São Paulo: Sumaré e Fapesp, 1994.

LIGHT, I.; BHACHU, P. Immigration and Entrepreneurship: Culture, Capital, and Ethnic Networks. New Brunswick, NJ: Transaction Publishers, 1993.

LIGHT, I.; KARAGEORGIS, S. The ethnic economy. In: SMELSER, N.; SWEDBERG, R. (Eds.). The Handbook of Economic Sociology. Princeton, NJ: Princeton University Press, 1994.

MARTES, A. C. B.; RODRIGUEZ, C. L. Afiliação religiosa e empreendedorismo étnico: o caso dos brasileiros nos Estados Unidos. Revista de Administração Contemporânea, Curitiba, v. 8, n. 3, p. 117-141, 2004.

MARTIN, J. Cultures in Organizations: Three Perspectives. New York and Oxford: Oxford University Press, 1992.

MARTINS, J. S. O cativeiro da terra. São Paulo: Ciências Humanas, 1979. 
PEREIRA, L. C. B. Origens étnicas e sociais do empresário paulista. Revista de Administração de Empresas, São Paulo, v. 11, n. 4, p. 83-106, 1964.

PESCATELlO, A. M. Both Ends of the Journey: An Historical Study of Migration and Change in Brazil and Portugal, 1889-1914. 167 p. Tese (Doutorado em Letras). University of California at Los Angeles, Los Angeles, 1970

ROWLEY, T.; BEHRENS, D.; KRACKHARDT, D. Redundant governance structures: an analysis of structural and relational embeddedness in the steel and semiconductor industries. Strategic Management Journal, v. 21, n. 3, p. 369-386, 2000.

SCHEIN, E. Organizational Culture and Leadership. San Francisco: JosseyBass, 1985.

SMELSER, N. J.; SWEDBERG, R. The sociological perspective on the economy. In: SMELSER, N. J.; SWEDBERG, R. The Handbook of Economic Sociology. Princeton, NJ: Princeton University Press, 1994.

SWEDBERG, R. Explorations in Economics Sociology. New York: Russel Sage Foundation, 1993.

TRUZZI, O. Etnias em convívio: o bairro do Bom Retiro em São Paulo. Estudos Históricos, v. 28, p. 143-166, 2001.
TRUZZI, O. Patrícios: sírios e libaneses em São Paulo. São Paulo: Hucitec 1996.

TRUZZI, O. Café e indústria: São Carlos (1850-1950). São Carlos: Universidade Federal de São Carlos, 1986.

TRUZZI, O. De mascates a doutores: sírios e libaneses em São Paulo. São Paulo: Sumaré, 1991.

UZZI, B. The sources and consequences of embeddedness for the economic performance of organizations: the network effect. American Sociological Review, v. 61, p. 674-698, 1996.

UZZI, B. Social structure and competition in interfirm networks: the paradox of embeddedness. Administrative Science Quarterly, v. 42, n. 1, p. 35-67, 1997.

WALDINGER, R.; WARD, R.; ALDRICH, H. Ethnic business and occupational mobility in advanced societies. Sociology, v. 19, n. 4, p. 586-597, 1985.

WARren, D. A industrialização de São Paulo. São Paulo: Difel, 1971.

ZUKIN, S.; DIMAGGIO, P. Structures of capital. Cambridge: Cambridge University Press, 1990.

Artigo recebido em 30.09.2005. Aprovado em 24.01.2007.

\section{Oswaldo Mário Serra Truzzi}

Professor do Departamento de Engenharia de Produção UFSCar. Doutor em Administração de Empresas pela FGV-EAESP e Pós-doutor em História pela Universidade de Chicago. Interesses de pesquisa nas áreas de sociologia econômica, redes étnicas, história e teoria das organizações.

E-mail: truzzi@power.ufscar.br

Endereço: Rod. Washington Luís, Km 235, Caixa Postal 676, São Carlos - SP, 13565-905.

\section{Mário Sacomano Neto}

Professor do Programa de Mestrado em Administração pela Universidade Metodista de Piracicaba. Doutor em Engenharia de Produção pela UFSCar. Visiting Scholar em Ciência Política pela Universidade de Chicago.

Interesses de pesquisa nas áreas de sociologia econômica, redes sociais, cadeias de suprimentos, teoria das organizações e estratégia.

E-mail: pmsn@terra.com.bre msacomano@unimep.br

Endereço: Rua Sete de Setembro, 3148, Centro, São Carlos - SP, 13560-181. 